\title{
BMJ open Prevalence of anal incontinence among Norwegian women: a cross-sectional study
}

\author{
Kathrine Rømmen, ${ }^{1,2,3}$ Berit Schei, ${ }^{1,4}$ Astrid Rydning, ${ }^{5}$ Abdul H Sultan,,${ }^{6,7}$ \\ Siv Mørkved ${ }^{1,2}$
}

To cite: Rømmen K, Schei B, Rydning $A$, et al. Prevalence of anal incontinence among Norwegian women:

a cross-sectional study. BMJ Open 2012;2:e01257. doi:10.1136/

bmjopen-2012-001257

- Prepublication history for this paper is available online. To view these files please visit the journal online (http:// dx.doi.org/10.1136/ bmjopen-2012-001257).

Received 11 April 2012 Accepted 26 June 2012

This final article is available for use under the terms of the Creative Commons Attribution Non-Commercial 2.0 Licence; see http://bmjopen.bmj.com

${ }^{1}$ Department of Public Health and General Practice, Norwegian University of Science and Technology, Trondheim, Norway ${ }^{2}$ Department of Clinical Service, Trondheim University Hospital, Trondheim, Norway

${ }^{3}$ Programme for

Physiotherapy, University College of Sør-Trøndelag, Trondheim, Norway

${ }^{4}$ Department of Gynecology, Trondheim University Hospital, Trondheim, Norway ${ }^{5}$ Department of Surgery, Trondheim University Hospital, Trondheim, Norway ${ }^{6}$ Department of Obstetrics and Gynaecology, Croydon University Hospital, Croydon, UK

${ }^{7}$ St.George's University of London, London, UK

Correspondence to Dr Kathrine Rømmen; kathrine.rommen@ntnu.no

\section{ABSTRACT}

Objective: Anal incontinence (Al) is a symptom associated with age, bowel symptoms and obstetric injuries. Primary aim of the study was to establish the prevalence of Al among women and secondarily to evaluate the impact on daily life and conditions associated with Al.

Design: A cross-sectional study.

Setting: Participants attended research stations located in different parts of Nord-Trøndelag county, Norway. Data were collected through interviews, questionnaires and clinical examinations.

Participants: In total, 40955 community-dwelling women aged 30 years and older were invited. A total of 25037 women participated, giving a participation rate of $61.1 \%$.

Primary and secondary outcome measures: Fecal incontinence and flatal incontinence was defined as involuntary loss of feces and flatus weekly or more, respectively. Al was defined as the involuntary loss of feces and/or flatus weekly or more. Urgency was defined as the inability to defer defecation for $15 \mathrm{~min}$. Statistical methods included prevalence estimates and logistic regression analysis.

Results: Questions about Al were completed by 20391 (82.4\%) women. Among the 20391 women, Al was reported by $19.1 \%$ ( $95 \% \mathrm{Cl} 18.6 \%$ to $19.7 \%$ ) and fecal incontinence was reported by $3.0 \%(95 \% \mathrm{Cl}$ $2.8 \%$ to $3.2 \%$ ). Urgency was experienced by 2586 women $(12.7 \%, 95 \% \mathrm{Cl} 12.2$ to 13.1$)$. Impact on daily life was stated by $794(26.0 \%, 95 \% \mathrm{Cl} 24.4$ to 27.5$)$ women with Al. In bivariate age-adjusted analysis of $\mathrm{Al}, \mathrm{OR}$ and $\mathrm{Cl}$ for urgency (OR $3.19,95 \% \mathrm{Cl} 2.92$ to 3.49 ) and diarrhoea (OR 3.81, 95\% Cl 3.32 to 4.38 ) revealed strongest associations with Al.

Conclusions: Al affects one in five women older than 30 years. Strongest associated symptoms are urgency and diarrhoea.

Trial registration number: The study was approved by the Regional Committee for Medical and Health Research Ethics (No. 2009/1214) and followed the Declaration of Helsinki.

\section{ARTICLE SUMMARY}

\section{Article focus}

- To estimate the prevalence of Al.

- To investigate the impact on daily life among women with Al.

- To establish associations and risk factors related to reproductive characteristics and gynaecological conditions, bowel disturbances, general health indicators and socio-demographic characteristics.

\section{Key messages}

- Bowel symptoms such as urgency and diarrhoea are strongly associated with both flatal and fecal incontinence (FI).

- $\mathrm{Al}$ is associated with experiencing three or more childbirths. There are no significant differences in prevalence of $\mathrm{Al}$ or $\mathrm{FI}$ between nulliparous women and primiparous women.

- Among women with $\mathrm{Fl}$, the severe impact on daily life is well known to the field. However, one of five women with $\mathrm{Al}$ also states that it has an impact on daily life.

Strengths and limitations of this study

- This study reports prevalence and associated factors from a very large sample size. The study addresses many potential associations and risk factors to Al.

- The study reports prevalence only among women.

\section{INTRODUCTION}

Anal incontinence (AI) is a symptom that is associated with several negative effects on social, physical, occupational and leisure activities and is associated with higher healthcare costs. ${ }^{1-5}$ The term AI is used when addressing uncontrolled passage of fecal material and/or flatus, while fecal incontinence (FI) is applied when only addressing passage of fecal material. ${ }^{6} 7$ Estimated prevalence of $\mathrm{AI}$ varies from $2 \%$ to $24 \%$, and the phenomenon is believed to be under-reported and a hidden problem in the adult population. ${ }^{6} 89$ In addition to patients 
who under-report their symptoms, the use of different score systems and the lack of a uniform definition of AI might cause the substantial variations in prevalence estimations. ${ }^{10}$ Studies have shown that the prevalence of fecal and flatal incontinence increases with age. ${ }^{4{ }^{11-18}}$ A review of 29 studies reported that FI was experienced by $1.6 \%$ of women aged $15-60$ years and $6.2 \%$ of women older than 60 years. ${ }^{11}$ However, as 17 of the studies did not include leakage of flatus, the prevalence of AI remained unclear.

Many studies have explored the relationship between childbirth and the development of AI, but results are conflicting. ${ }^{4}{ }^{18-20}$ In a recent systematic review, the authors concluded that third- or fourth-degree sphincter rupture was associated with postpartum FI. ${ }^{21}$ However, since the studies included in the review had a wide range of length of follow-up, the relative importance and interactions with other risk factors such as age were difficult to assess.

Menopause and several pelvic floor disorders such as urinary incontinence and pelvic organ prolapse (POP) have also been associated with FI. ${ }^{12}{ }^{22-26}$ Other risk factors associated with FI include high body mass index (BMI), bowel disturbances and several chronic diseases. ${ }^{12} 13171927-30$

The primary aim of this study was to estimate the prevalence of AI among women in a population that is well studied and documented in several aspects of general health. The secondary aims were to investigate the impact on daily life and establish associations and risk factors related to reproductive characteristics and gynaecological conditions, bowel disturbances, general health indicators and socio-demographic characteristics.

\section{METHODS}

A cross-sectional population-based health survey (HUNT 3) was carried out in Nord-Trøndelag County, Norway, between October 2006 and June 2008. The county is regarded as representative of the Norwegian population and suitable for survey, but the inhabitants have an income and educational level slightly below average. ${ }^{31}$

Data were collected through questionnaires and clinical examinations and interviews.

Questionnaire 1 (Q1) was sent by postal mail with the invitation to participate in the health survey. It was returned personally when participants attended the screening stations for clinical examinations and interviews. Among 40955 eligible community-dwelling women aged 30 years and older, 25037 (61.1\% participation rate) attended the screening stations and responded to Q1. The number of women excluded from the study and the final study population is illustrated in a flowchart (figure 1).

Information about age, height, weight and general selfrated health status was collected from Q1. After exploring the study population for distribution of AI according to the different age categories, age was categorised in 10-year age intervals. Height and weight were measured when the participants attended the screening stations. BMI was computed as weight (in kilograms) divided by height squared (in square metres). Subjects were grouped into four different BMI categories to represent normal weight $\left(<25 \mathrm{~kg} / \mathrm{m}^{2}\right)$, overweight $\left(25-29.9 \mathrm{~kg} / \mathrm{m}^{2}\right)$, obesity class $I$ $\left(30-34.9 \mathrm{~kg} / \mathrm{m}^{2}\right)$ and obesity class II $\left(\geq 35 \mathrm{~kg} / \mathrm{m}^{2}\right)$. Selfrated general health status was assessed using the question 'how is your health now?' with response categories poor/not so good/good/very good.
Figure 1 Flowchart for the study population. Q1, questionnaire 1; Q2, Q1, questionnaire 2.

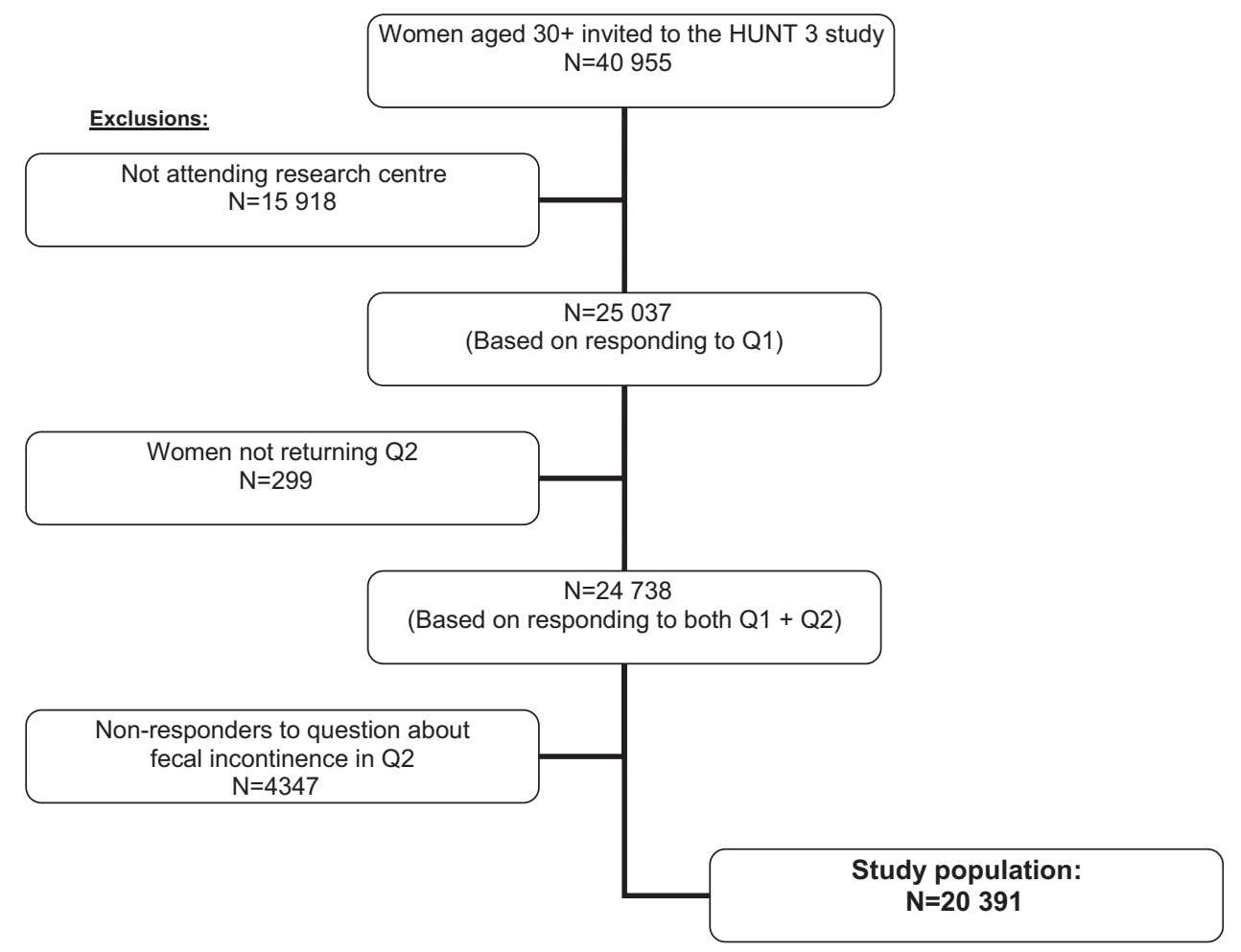


Questionnaire 2 (Q2), which was age and gender specific, was given to the participants when attending. The participants could choose to fill in and return $Q^{2}$ at the screening station or to fill in at home and return the questionnaire by postal mail. In Q2, the instrument assessing AI was introduced as one of many different health-related topics for women in age categories 30-69 and $70+$ years (figure 2 ). The women were asked to indicate whether they experienced involuntary leakage weekly or daily. We defined FI as experiencing involuntary leakage of any stool weekly or more often during the last month. Furthermore, women experiencing involuntary leakage of gas weekly or more often during the last month were considered to have flatal incontinence. AI was defined as reporting fecal and/or flatal incontinence weekly or more often during the last month. Women reporting that the incontinence had an impact on their daily life weekly or more often were recognised as having bothersome incontinence. We defined urgency as the inability to defer defecation for $15 \mathrm{~min}$. Women answering 'no' to the question 'Are you able to defer defecation and toilet visit for $15 \mathrm{~min}$ after first feeling the need to go?' were categorised as having urgency. Data about urinary incontinence were collected by asking the women 'Do you experience involuntarily leakage of urine?'. Women answering 'yes' to this question were asked to indicate 'How often do you experience urinary leakage?' with the following alternatives: less than once a month/more than once a month/ once a week or more/each day and/or night. Women reporting urinary leakage weekly or more often were considered incontinent to urine. Information about pelvic surgery treatments and menopause was obtained with the questions: 'Have you ever received surgical treatment for pelvic organ prolapse?' and 'Have you ever had surgery treatment to remove the entire uterus?'. Responders answering 'no' and 'I do not know' and missing responders were defined as to not having these conditions. Menopausal women were identified as the women answering the section about menopause. There was an independent instrument measuring several bowel symptoms. The questions addressing diarrhoea, constipation and mixed diarrhoea and constipation were: 'to which degree have you experienced...diarrhoea/constipation/ mixed diarrhoea and constipation ... the last 12 months?'. Frequency categories were never/some/a lot. Those who reported a lot of diarrhoea and/or constipation during the past 12 months were categorised as experiencing diarrhoea and/or constipation, respectively.
Parity was reported in the interview session at the screening station. The question used by the interviewers was 'Have you ever been pregnant? If yes, How many children have you given birth to?'.

Data from HUNT 3 were linked to the Norwegian National Education Database to extract information about educational level among the women. Educational levels were constructed in accordance to the tripartition of educational levels in Norwegian Standard Classification of Education (revised 2000): compulsory education ( $\leq 10$ th class level), intermediate education $(11-14$ th class level) and tertiary education ( $\geq 14$ th class level).

As FI is a more rare phenomenon than flatal incontinence, women responding to the question about FI $(n=20391)$ defined the study population in this paper. Women in the study population who did not answer the question about flatal incontinence $(n=150)$ were considered not to have flatal incontinence. The responders and non-responders to the question about FI were compared on several background variables, including mean BMI, parity, age and educational level. Non-responders were not included in further statistical analysis.

\section{Statistical analysis}

Statistical methods included estimating prevalence in percentages with $95 \%$ CIs. Prevalence of impact on daily life among women with AI and FI was reported as valid percentages with $95 \% \mathrm{CI}$, due to missing responses to question about impact on daily life. Logistic regression analysis was conducted to measure strength of association and to identify possible risk factors. Variables significantly associated with flatal incontinence and FI in prevalence estimations were entered as categorical variables in crude and bivariate regression analysis. In multivariate logistic regression analysis of parity as a risk factor for FI, we adjusted for age and education level. In addition, interactions between parity and surgery treatment for POP and between parity and BMI were entered to the same multivariate analysis. Significance level in multivariate analysis was $\mathrm{p}<0.05$. The data set was analysed using SPSS V.17 (SPSS Inc).

\section{RESULTS}

Questionnaire 2(Q2) was returned by 24738 of the participants. The question about FI was completed by 20391 women, giving a response rate of $82.4 \%$ to the section about AI in Q2. The non-responders to the
Figure 2 Questions about anal incontinence applied in HUNT 3.

\begin{tabular}{|l|l|}
\hline & Never/rare \\
\hline $\begin{array}{l}\text { Have you been experiencing involuntary leakage of gas from the } \\
\text { bowels the last month? (\%) }\end{array}$ & $\begin{array}{l}\text { Every } \\
\text { week }\end{array}$ \\
\hline $\begin{array}{l}\text { Have you been experiencing involuntary leakage of stool from the } \\
\text { bowels the last month? }\end{array}$ & \\
\hline $\begin{array}{l}\text { If yes to any of the two prior questions - does the leakage affect } \\
\text { your daily life? }\end{array}$ & \\
\hline $\begin{array}{l}\text { Are you able to defer defecation and toilet visit for } 15 \text { minutes after } \\
\text { first feeling the need to go? }\end{array}$ & \\
\hline
\end{tabular}


section about AI did not differ significantly from the responders regarding mean BMI and parity (data not shown). Mean age among the non-responders versus the responders was 55.0 years (95\% CI 54.6 to 55.5 ) and 55.8 years (95\% CI 55.6 to 56.0 ), respectively. There was a significant difference between the percentages of nonresponders and responders with a tertiary educational level $(3.7 \%, 95 \%$ CI 3.1 to 4.2 and $5.8 \%$, 95\% CI 5.4 to 6.1 , respectively). Response rates in age categories varied from $70.6 \%$ to $86.4 \%$, with the highest response rate for women in age categories $60-69$ years and $50-59$ years ( $86.4 \%$ and $82.9 \%$, respectively). Women in the age categories $80+$ years and $30-39$ years had the lowest response rate $(70.6 \%$ and $76.3 \%$, respectively).

\section{Prevalence of $\mathrm{Al}, \mathrm{FI}$ and the impact on daily life}

In total, $19.1 \%(n=3899)$ of the women reported AI, while $3.0 \%(n=608)$ reported FI (table 1$)$. Table 1 shows the distribution of AI, FI, flatal incontinence, urgency and impact on daily life in the different age categories. A total of 608 women $(3.0 \%)$ reported FI. Furthermore, FI was experienced daily by $98(0.5 \%)$ women, whereas 510 $(2.5 \%)$ stated that they had FI weekly. Among the women experiencing FI, 474 experienced additional flatal incontinence. Flatal incontinence was reported daily by $1041(5.1 \%)$ women, while 2724 (13.4\%) reported flatal incontinence weekly. The prevalence gradually increased with age, from $14.7 \%$ (95\% CI 13.4\% to $15.9 \%$ ) among women aged $30-39$ years to $21.6 \%$ (95\% CI $19.1 \%$ to $24.2 \%$ ) among women aged $80+$ years.

The question about impact on daily life was answered by 3056 of the 3899 women with AI. Twenty six per cent (794/3056) of the women stated that AI had an impact on daily life weekly or more. Among women experiencing both fecal and flatal incontinence, $60.4 \%$ (270/ 447) reported an impact on daily life weekly or more. The amount of women reporting impact on daily life when experiencing only FI was $42.5 \%$ (54/127), whereas $18.9 \%(470 / 2482)$ of women experiencing only flatal incontinence reported an impact on daily life weekly or more.

\section{Obstetrics and gynaecological factors}

The prevalence of AI did not significantly differ between nulliparous women, primiparous women and women with a subsequent childbirth (table 2). Among women experiencing three or more deliveries, the prevalence of AI was significantly higher (20.7\%, 95\% CI 19.9 to 21.5$)$. There was a significant difference in prevalence of FI between women reporting two childbirths $(2.5 \%, 95 \%$ CI 2.2 to 2.9) and women reporting three or more childbirths $(3.4 \%, 95 \%$ CI 3.1 to 3.8). Menopause was associated with a significantly higher prevalence of both $\mathrm{AI}$ and FI, the same was observed among women reporting to have had surgical treatment for POP. Among women who had a hysterectomy, a significantly higher prevalence of AI was observed, but there was no significant difference for FI.

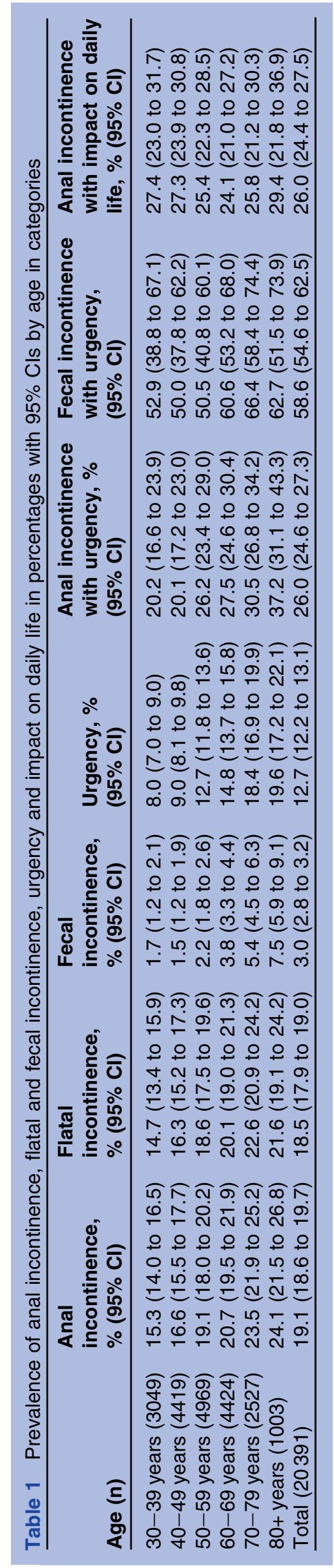




\section{Bowel symptoms}

In total, urgency was experienced by 2586 (12.7\%) women. As shown in table 1, the prevalence of urgency increased with age. Among women with AI, 26\% reported urgency, while this was the case for $58.6 \%$ of women with FI. Women reporting a lot of diarrhoea within the past 12 months had a significantly higher prevalence of both AI and FI (table 2). Furthermore, women reporting a lot of constipation had a significantly higher prevalence of AI than other women $(32.7 \%, 95 \%$ CI 30.4 to 34.9 vs $17.9,95 \%$ CI 17.4 to 18.5$)$. Responders reporting mixed diarrhoea and constipation had higher prevalence of both AI and FI compared with women not reporting these symptoms.
General health aspects and socio-demographic factors

Women at intermediate education level had a higher prevalence of both AI and FI compared with women at compulsory education level (table 2). Women in obesity class II had a significantly higher prevalence of AI than normal weight women, while the prevalence of FI increased significantly in women in obesity class I compared with normal weight women. Among women reporting a poor self-rated health, $33.6 \%$ (95\% CI $28.0 \%$ to $39.2 \%$ ) of the women experienced AI, whereas $12.7 \%$ (95\% CI $11.5 \%$ to $14.0 \%$ ) of the women with very good self-rated health reported AI. Those women experiencing urinary incontinence weekly or more had a significantly higher prevalence of AI

Table 2 Prevalence of anal, flatal and fecal incontinence in percentages with $95 \%$ Cls by general health parameters, reproductive characteristics and bowel symptoms

\begin{tabular}{|c|c|c|c|}
\hline Variable (n) & $\begin{array}{l}\text { Anal incontinence, } \\
\%(95 \% \mathrm{Cl})\end{array}$ & $\begin{array}{l}\text { Flatal incontinence, } \\
\%(95 \% \mathrm{Cl})\end{array}$ & $\begin{array}{l}\text { Fecal incontinence, } \\
\%(95 \% \mathrm{Cl})\end{array}$ \\
\hline \multicolumn{4}{|l|}{ Educational level } \\
\hline Compulsory (11974) & $17.4(16.7$ to 18.1$)$ & $16.8(16.1$ to 17.5$)$ & 2.6 (2.3 to 2.9$)$ \\
\hline Intermediate (7150) & 21.2 (20.2 to 22.2 ) & 20.5 (19.6 to 21.5 ) & 3.5 (3.1 to 3.9$)$ \\
\hline Tertiary (1169) & 24.0 (21.6 to 26.5$)$ & 23.4 (20.9 to 25.8$)$ & 3.5 (2.5 to 4.6$)$ \\
\hline \multicolumn{4}{|l|}{ Body mass index } \\
\hline Normal weight (7482) & 18.2 (17.3 to 19.0$)$ & 17.6 (16.7 to 18.5$)$ & 2.4 (2.1 to 2.8$)$ \\
\hline Overweight (7933) & 19.5 (18.6 to 20.4$)$ & $18.8(18.0$ to 19.7$)$ & 2.9 (2.5 to 3.2$)$ \\
\hline Obesity class I (3522) & 19.5 (18.2 to 20.8$)$ & 18.9 (17.6 to 20.2$)$ & 4.0 (3.3 to 4.6$)$ \\
\hline Obesity class II (1352) & 21.4 (19.2 to 23.6$)$ & 20.1 (18.0 to 22.3 ) & 3.6 (2.6 to 4.6$)$ \\
\hline \multicolumn{4}{|l|}{ Self-rated health } \\
\hline Poor (274) & 33.6 (28.0 to 39.2$)$ & 32.1 (26.6 to 37.7 ) & 9.9 (6.3 to 13.4$)$ \\
\hline Not so good (5491) & 25.0 (23.9 to 26.2 ) & 24.2 (23.1 to 25.3 ) & 4.7 (4.1 to 5.2$)$ \\
\hline Good (10866) & 17.3 (16.6 to 18.0$)$ & 16.6 (15.9 to 17.3$)$ & 2.4 (2.1 to 2.7$)$ \\
\hline Very good (2881) & 12.7 (11.5 to 14.0$)$ & 12.4 (11.2 to 13.6$)$ & 1.0 (0.6 to 1.4$)$ \\
\hline \multicolumn{4}{|l|}{ Urinary incontinence } \\
\hline Yes (2459) & 34.2 (32.4 to 36.1$)$ & 33.0 (31.1 to 34.8$)$ & 7.8 (6.7 to 8.8$)$ \\
\hline No (3376) & 24.5 (23.0 to 25.9$)$ & 23.6 (22.2 to 25.1$)$ & 3.0 (2.4 to 3.5$)$ \\
\hline \multicolumn{4}{|l|}{ Parity } \\
\hline Nulliparous (1448) & 17.3 (15.4 to 19.3$)$ & $16.8(14.9$ to 18.7$)$ & 3.0 (2.2 to 3.9$)$ \\
\hline 1 childbirth (1760) & 17.3 (15.5 to 19.0$)$ & 16.7 (15.0 to 18.5$)$ & 2.6 (1.9 to 3.4$)$ \\
\hline 2 childbirths (7575) & $17.9(17.0$ to 18.8$)$ & $17.2(16.4$ to 18.1$)$ & 2.5 (2.2 to 2.9$)$ \\
\hline$\geq 3$ childbirths $(9608)$ & 20.7 (19.9 to 21.5$)$ & 20.0 (19.2 to 20.8$)$ & 3.4 (3.1 to 3.8$)$ \\
\hline \multicolumn{4}{|l|}{ Menopausal } \\
\hline Yes (12612) & 21.1 (20.4 to 21.8$)$ & 20.3 (19.6 to 21.0$)$ & 3.7 (3.3 to 4.0$)$ \\
\hline No (7779) & $15.9(15.1$ to 16.7$)$ & $15.3(14.5$ to 16.2$)$ & 1.7 (1.4 to 2.0$)$ \\
\hline \multicolumn{4}{|l|}{ Pelvic surgery } \\
\hline \multicolumn{4}{|l|}{ Pelvic organ prolapse } \\
\hline Yes (1060) & $30.9(28.1$ to 33.6$)$ & 29.9 (27.1 to 32.7$)$ & 7.1 (5.5 to 8.6$)$ \\
\hline No (19331) & 18.5 (17.9 to 19.0$)$ & $17.7(17.2$ to 18.3$)$ & 2.8 (2.5 to 3.0$)$ \\
\hline \multicolumn{4}{|l|}{ Hysterectomy } \\
\hline Yes (892) & 23.7 (20.9 to 26.5$)$ & 22.5 (19.8 to 25.3 ) & 3.5 (2.3 to 4.7$)$ \\
\hline No (19499) & $18.9(18.4$ to 19.5$)$ & $18.2(17.6$ to 18.7$)$ & 3.0 (2.7 to 3.2$)$ \\
\hline \multicolumn{4}{|l|}{ Diarrhoea } \\
\hline Never/some (10365) & $18.0(17.4$ to 18.5$)$ & $17.4(16.9$ to 17.9$)$ & 2.4 (2.2 to 2.6$)$ \\
\hline A lot (873) & 44.9 (41.6 to 48.2$)$ & 42.5 (39.2 to 45.8$)$ & $16.0(13.6$ to 18.5$)$ \\
\hline \multicolumn{4}{|l|}{ Constipation } \\
\hline Never/some (18710) & $17.9(17.4$ to 18.5$)$ & $17.2(16.7$ to 17.8$)$ & 2.9 (2.7 to 3.2$)$ \\
\hline A lot (1681) & 32.7 (30.4 to 34.9$)$ & 32.1 (29.8 to 34.3$)$ & 3.8 (2.8 to 4.7$)$ \\
\hline \multicolumn{4}{|c|}{ Both diarrhoea and constipation } \\
\hline Never/some (19710) & $18.4(17.8$ to 18.9$)$ & 17.7 (17.1 to 18.3$)$ & 2.7 (2.5 to 2.9 ) \\
\hline A lot $(681)$ & 41.4 (37.7 to 45.1$)$ & 39.4 (35.7 to 43.0$)$ & 11.5 (9.1 to 13.9$)$ \\
\hline
\end{tabular}


(34.2\%, $95 \%$ CI 32.4 to 36.1$)$ and FI $(7.8 \%, 95 \%$ CI 6.7 to 8.8 ).

\section{Univariate, bivariate and multivariate logistic regression} analysis

Table 3 shows ORs for variables associated with flatal incontinence and FI. In age-adjusted regression analysis, significant associations with flatal incontinence were found related to educational level, urinary incontinence, three or more childbirths, menopause, surgical treatment for POP, hysterectomy, urgency, diarrhoea and mixed diarrhoea and constipation. A linear trend was observed between number of childbirths and flatal incontinence. Variables significantly associated with FI in age-adjusted analysis were obesity class I, urinary incontinence, surgery treatment for POP, urgency, diarrhoea and mixed diarrhoea and constipation.

Results from the multivariate analysis of parity as an exposure to FI showed that OR for primiparous women was 0.70 (95\% CI 0.36 to 1.35); for women with one subsequent childbirth, the OR was 0.94 (95\% CI 0.63 to $1.41)$; and for women experiencing three or more childbirths, the OR was 0.85 (95\% CI 0.57 to 1.27 ). None of the parity categories reached a p level of $<0.05$.

\section{DISCUSSION}

In this large population-based study, we found that $19.1 \%$ of the women experienced AI, whereas FI was reported by $3.0 \%$ of the women. Among the women experiencing AI, $26 \%$ of the women stated that the incontinence affected their daily life weekly or more. Several associations and risk factors were identified, and urgency and diarrhoea were the variables with strongest association to both AI and FI. In multivariate regression analysis, parity was not found to be an independent risk factor for AI.

\section{Limitations to the study}

The participation rate in HUNT 3 among women aged $30+$ years was $61.1 \%$. In general, the people accepting to participate in a health survey, including examinations, interviews and questionnaires might be more aware of health-related issues than those choosing not to attend, hereby representing a potential selection bias. However,

Table 3 ORs and $95 \%$ Cls for variables associated with flatal and fecal incontinence

\begin{tabular}{|c|c|c|c|c|}
\hline \multirow[b]{2}{*}{ Variable } & \multicolumn{2}{|l|}{ Flatal incontinence } & \multicolumn{2}{|l|}{ Fecal incontinence } \\
\hline & Crude OR $(95 \% \mathrm{Cl})$ & Adjusted OR* $(95 \% \mathrm{Cl})$ & Crude OR $(95 \% \mathrm{Cl})$ & Adjusted OR* $(95 \% \mathrm{Cl})$ \\
\hline \multicolumn{5}{|l|}{ Age, years } \\
\hline $30-39$ & - & & - & \\
\hline $40-49$ & $1.13(0.99$ to 1.28$)$ & & $0.92(0.64$ to 1.33$)$ & \\
\hline $50-59$ & $1.33(1.17$ to 1.50$)$ & & $1.29(0.92$ to 1.81$)$ & \\
\hline $60-69$ & 1.47 (1.30 to 1.66$)$ & & 2.35 (1.71 to 3.22$)$ & \\
\hline $70-79$ & $1.70(1.48$ to 1.94$)$ & & 3.37 (2.43 to 4.67$)$ & \\
\hline $80+$ & 1.61 (1.34 to 1.93$)$ & & 4.75 (3.30 to 6.83$)$ & \\
\hline \multicolumn{5}{|l|}{ Education level } \\
\hline Compulsory & - & - & - & - \\
\hline Intermediate & 1.28 (1.19 to 1.38$)$ & 1.16 (1.07 to 1.27$)$ & $1.34(1.13$ to 1.59$)$ & $0.98(0.82$ to 1.19$)$ \\
\hline Tertiary & 1.51 (1.31 to 1.74$)$ & $1.33(1.14$ to 1.55$)$ & $1.35(0.97$ to 1.87$)$ & $0.84(0.60$ to 1.19$)$ \\
\hline Obesity class I & 1.09 (0.98 to 1.21$)$ & $1.03(0.93$ to 1.14$)$ & 1.47 (1.23 to 1.75$)$ & 1.36 (1.14 to 1.63$)$ \\
\hline Obesity class II & 1.18 (1.02 to 1.36$)$ & 1.14 (0.98 to 1.32$)$ & 1.25 (0.93 to 1.69$)$ & $1.23(0.92$ to 1.67$)$ \\
\hline Urinary incontinence & 1.59 (1.42 to 1.78$)$ & 1.50 (1.33 to 1.69$)$ & 2.77 (2.16 to 3.55$)$ & 2.21 (1.71 to 2.87$)$ \\
\hline \multicolumn{5}{|l|}{ Parity (in categories) } \\
\hline Nulliparous & - & - & - & - \\
\hline 1 childbirth & 0.99 (0.83 to 1.20$)$ & $1.00(0.83$ to 1.21$)$ & 0.86 (0.56 to 1.30$)$ & $0.94(0.62$ to 1.43$)$ \\
\hline 2 childbirths & $1.03(0.89$ to 1.20$)$ & 1.04 (0.89 to 1.21$)$ & $0.82(0.59$ to 1.15$)$ & $0.92(0.66$ to 1.29$)$ \\
\hline$\geq 3$ childbirths & 1.24 (1.07 to 1.44$)$ & 1.18 (1.02 to 1.37$)$ & $1.13(0.82$ to 1.55$)$ & $1.04(0.75$ to 1.43$)$ \\
\hline Parities (continuous) & $1.10(1.06$ to 1.15$)$ & 1.08 (1.03 to 1.12$)$ & 1.11 (1.01 to 1.22$)$ & $1.04(0.94$ to 1.14$)$ \\
\hline Menopause & $1.40(1.30$ to 1.51$)$ & 1.26 (1.11 to 1.42$)$ & 2.25 (1.85 to 2.73$)$ & $1.31(0.95$ to 1.79$)$ \\
\hline $\begin{array}{l}\text { Menopause, adjusted } \\
\text { for oestrogen treatment }\end{array}$ & 1.35 (1.25 to 1.46$)$ & $1.22(1.07$ to 1.38$)$ & 2.16 (1.77 to 2.64$)$ & $1.26(0.92$ to 1.73$)$ \\
\hline $\begin{array}{l}\text { Surgical treatment for } \\
\text { pelvic organ prolapse }\end{array}$ & 1.98 (1.73 to 2.27$)$ & 1.78 (1.54 to 2.04$)$ & 2.74 (2.13 to 3.52$)$ & 1.87 (1.44 to 2.42 ) \\
\hline Hysterectomy & $1.31(1.12$ to 1.54$)$ & $1.17(0.99$ to 1.38$)$ & $1.22(0.84$ to 1.76$)$ & $0.88(0.60$ to 1.27$)$ \\
\hline Urgency & 3.07 (2.80 to 3.35$)$ & 2.96 (2.70 to 3.24$)$ & $11.12(9.41$ to 13.14$)$ & $10.00(8.44$ to 11.84$)$ \\
\hline Diarrhoea & 3.51 (3.06 to 4.04$)$ & 3.59 (3.12 to 4.12$)$ & 8.27 (6.72 to 10.17$)$ & $8.67(7.02$ to 10.71$)$ \\
\hline Constipation & 2.27 (2.03 to 2.53 ) & 2.26 (2.02 to 2.52$)$ & $1.30(1.00$ to 1.69$)$ & $1.25(0.95$ to 1.63$)$ \\
\hline $\begin{array}{l}\text { Mixed diarrhoea and } \\
\text { constipation }\end{array}$ & 3.01 (2.57 to 3.53$)$ & 3.05 (2.60 to 3.57$)$ & 4.68 (3.64 to 6.02$)$ & 5.23 (4.05 to 6.76$)$ \\
\hline
\end{tabular}


this was compensated by the large sample size and good response rate to the section including questions about AI. In addition, the questionnaires were constructed to investigate many health-related topics, hence reducing the bias of having a higher proportion of women with incontinence responding to the incontinence section in the questionnaire. We found a statistically significant difference in mean age between the non-responders and responders of 8 months. Although advancing age is associated with an increasing prevalence of $\mathrm{AI}$, it is unlikely that the mean age difference will influence the results. There were a significantly lower percentage of women with high educational level among the nonresponders, but the overall number of women with high education level was low and they did not reflect the majority of the women in the study population. Women living in nursing homes were not included in our study population, and as former studies have shown an increased prevalence among nursing home residents, this might have caused an underestimation. ${ }^{32}$ However, we did not include women aged $<30$ years neither, which, on the other hand could have decreased the prevalence estimates. Some of the included women might have received successful treatment for a previous incontinence problem, thereby causing an underestimation of the association between some of the potential risk factors and AI.

Although the survey questions about AI were not validated, there was no Norwegian questionnaire available at the time. However, the questions represent cornerstone issues in measuring AI, and they are clearly formulated and easy to understand for the participants. As the survey did not enquire about former treatment for severe incontinence, some of the included women might have received successful treatment for a previous incontinence problem, thereby causing an underestimation of the association between some of the potential risk factors and AI. Given that our study lacked data about time of onset of AI, sphincter tears and delivery mode, our findings regarding the importance of sphincter tears and vaginal deliveries as a risk factor for developing late-onset AI remains inclusive.

Related to most of the questions assessed in this study, the responders reported different aspects of current health. As for variables requiring recall of former health issues, participants were asked to report major events (ie, parity, previous surgery) and therefore the issues are unlikely to be forgotten.

We found a substantially lower prevalence of FI in our study population compared with a community-based study including 1961 women aged $20+$ years where $9.0 \%$ of the women reported FI. ${ }^{12}$ However, the author defined FI by at least monthly leakage of any stool. In another population-based study, $2.8 \%$ of the women reported FI weekly or more, which is comparable to our results, but the author stated that results for the frequency category once per week were unreliable due to relative SE. ${ }^{13}$ The prevalence estimates in our study are higher than what was reported in a large communitybased study, including 10116 women and men. ${ }^{15}$ In the previous study, $1.7 \%$ of the women aged $40+$ years experienced FI weekly or more, adding up to $3.0 \%$ when including respondents having FI monthly or more. Moreover, the differences in prevalence estimates between our results and other studies could be partly explained by different use of definitions and score systems.

Among women experiencing both FI and flatal incontinence at the same time, more than half of the women claimed that the incontinence had an impact on their daily life. These results correspond well to results from a community-based study including 5483 women. ${ }^{15}$ Approximately every fifth woman who reported only flatal incontinence in our study stated that the incontinence had an impact on daily life. These findings highlight that flatal incontinence is considered a bothersome phenomenon among women. Furthermore, it is a common assumption that AI has a greater impact on daily life among younger women, as they might be more concerned with intimacy, social integration and being employed. However, we did not find significant differences regarding impact on daily life.

Our results support that women experiencing three or more childbirths have a higher prevalence of AI. These findings are similar to results in other studies. ${ }^{14}{ }^{33} \mathrm{We}$ did not find any significant differences between nulliparous women and primiparous women, but we found a linear trend between number of childbirths and increasing prevalence of AI after adjusting for age. It is possible that increasing number of childbirths has negative effects on pelvic floor muscle function, resulting in a higher prevalence of AI. In multivariate analysis, we did not identify parity as an independent risk factor for AI, supporting the findings of a populationbased study among 2800 women aged 20 years and older. ${ }^{4}$ The authors found no significant associations between FI and number of vaginal or vacuum-assisted deliveries and suggest that FI in women is attributed to 'multiple hits' wherein one insult could be augmented later in life by other factors (ie, non-obstetric anal injury, rectal urgency, diarrhoea and ageing). This is also highlighted in a summary of the epidemiology of FI, where the author states that comorbid disease is reported as a significant component in incontinence risk. ${ }^{34}$

The association between menopause and AI is rarely approached in prevalence studies of AI. We found that being menopausal was significantly associated with AI, still after adjusting for age and oestrogen treatment. In a recent cross-sectional study, among 332 women, menopause was found to be an independent risk factor for FI, but the risk of FI did not increase among women aged 60 years and older. ${ }^{24}$ FI was defined as involuntary leakage of stool and/or flatus, thus the results could be comparable to our definition of AI. However, the women were categorised as being incontinent if they had 
experienced symptoms within the past 4 weeks. Our definition of AI was based on experiencing symptoms weekly or more, which is a more conservative measure of incontinence frequency. Nevertheless, we found age and menopause to be independently associated with AI, and the prevalence increased significantly among women aged 70 years and older.

The association between POP and FI is well established..$^{12}$ Our study demonstrates that in spite of surgery for POP, these women are still at a higher risk of experiencing AI and FI. Possibly, the women seeking help for POP are likely to have had pre-existing incontinence prior to the surgery.

We found that urgency was the variable most strongly associated with AI and FI. This concurs with the findings of another population-based study including 2800 women. ${ }^{4}$ However, rectal urgency was defined as 'the need to rush to the toilet often or usually because of an urgent need to empty the bowels', whereas our definition of urgency was related to an inability to defer defecation for $15 \mathrm{~min}$, not to a sudden need to empty the bowels. Hereby we cannot claim that we have measured the same attribute. The number of women who experienced urgency was substantially higher than those experiencing FI, leading to an assumption that many women with urgency take precautions in their daily life to stay continent to fecal material. Diarrhoea was also strongly associated with AI and FI. The findings support the reported associations found in a previous population-based study including 2229 women and a nested case-control study, respectively. ${ }^{13}{ }^{19}$ In the nested case-control study, the cases had different degrees of severity, ranging from mild to severe. ${ }^{19}$ Definition of severity was based on a combination of frequency, amount and type, making it difficult to compare with our findings. Both authors reported only an association between diarrhoea and FI, whereas we additionally found a significant association between diarrhoea and AI. Mixed constipation and diarrhoea could signify irritable bowel syndrome, but the questions used in our study cannot be used to confirm the diagnosis as defined by the Rome II criteria. Nevertheless, our results show that women reporting change in frequency and consistency of stools is associated with a higher prevalence of both AI and FI.

Women in obesity class II had a significantly higher prevalence of AI compared with normal weight women, while women in obesity class I had a significantly higher prevalence of FI. These results lead to an assumption that AI, a variable that is made up of women mainly experiencing flatal incontinence, is associated with a higher BMI than what is the case for FI. To our knowledge, there are no other studies reporting these differences, and we cannot readily provide explanations to these results. Having a high BMI is considered to have deteriorating consequences to many health-related issues, and AI has previously been found to be associated with obesity. ${ }^{27} 35$ However, the cited studies reported results from condition-specific subgroups of women, and the results cannot be compared with findings in our population-based study.

Both AI and FI were associated with poor self-rated health and our findings concur with another study among community-dwelling older adults. ${ }^{5}$ The author concluded that there was a significant association between FI and poor self-received health among women, whereas we additionally found this association for AI.

Our study supports the contention that women experiencing urinary incontinence weekly or more have a higher prevalence of AI than those experiencing urinary incontinence less than weekly. This association has been shown in other studies, including a populationbased study in which the estimated OR was almost similar to our estimates. ${ }^{13}$

\section{CONCLUSIONS}

This study has provided a thorough investigation of AI related to age, general health parameters, reproductive characteristics and bowel symptoms in a large community-based study population. AI occurred among 19.1\% of the women and the prevalence increased with age. It affected the daily life of approximately every forth women experiencing AI, regardless of age categories. The prevalence of FI was $3.0 \%$.

Urgency and diarrhoea are the variables strongest associated with $\mathrm{AI}$ and $\mathrm{FI}$, and the results from this prevalence study therefore indicate the importance of conservative measures (eg, regulating bowel habits) in women experiencing AI. Women experiencing three or more childbirths had a significantly increased prevalence of AI, but there was no association between parity and FI. Further investigations are necessary to detect the true effect of obstetric injuries to late-onset $\mathrm{AI}$ in a community-based population.

Acknowledgements We thank the administration office of HUNT, all the women participating in the health survey and the Norwegian University of Science and Technology for financing the study.

Contributors BS, AR and SM drafted the original project protocol. KR conducted the analysis and drafted the article. BS, AR, SM and AS contributed to the analysis and interpretation of data, and critical revision of the manuscript for important intellectual content.

Funding The trial was supported by the Norwegian University of Science and Technology, Faculty of Medicine, Department of Public Health and General Practice (grant number 817089 00).

\section{Competing interests None.}

Ethics approval The study was approved by the Regional Committee for Medical and Health Research Ethics (No. 2009/1214) and followed the Declaration of Helsinki.

Provenance and peer review Not commissioned; externally peer reviewed.

Data sharing statement Technical appendix, statistical code and data set are available from the corresponding author at kathrine.rommen@ntnu.no. Participants gave informed consent for data sharing.

\section{REFERENCES}

1. Bharucha A. Fecal incontinence. Gastroenterology 2003;124:1672-85. 
2. Bharucha A, Zinsmeister A, Locke G, et al. Symptoms and quality of life in community women with faecal incontinence. Clin Gastroenterol Hepatol 2006;4:1004-9.

3. Dunivan GC, Heymen S, Palsson OS, et al. Fecal incontinence in primary care: prevalence, diagnosis, and health care utilization. $A m \mathrm{~J}$ Obstet Gynecol 2010;202:e1-6.

4. Bharucha A, Zinsmeister A, Locke GR, et al. Risk factors for fecal incontinence: a population-based study in women. $A m ~ J$ Gastroenterol 2006:101:1305-12.

5. Goode PS, Burgio KL, Halli AD, et al. Prevalence and correlates of fecal incontinence in community-dwelling older adults. J Am Geriatr Soc 2005;53:629-35.

6. Macmillan A, Merrie A, Marshall R, et al. The prevalence of fecal incontinence in community-dwelling adults; a systematic review of the literature. Dis Colon Rectum 2004:47:1341-9.

7. Whitehead W, Wald A, Norton N. Treatment options for fecal incontinence. Dis Colon Rectum 2001:44:131-42, discussion 42-4.

8. Valbø A, Kristoffersen $M$. Anal sphincter rupture during vaginal delivery. Tidsskr Nor Lægeforen 2005;125:591-3.

9. MacArthur C, Bick DE, Keighly MR. Faecal incontinence after childbirth. Br J Obstet Gynaecol 1997;104:46-50.

10. Madoff RD, Parker SC, Varma MG, et al. Faecal incontinence in adults. Lancet 2004;364:621-32.

11. Pretlove S, Radley S, Toozs-Hobson PM, et al. Prevalence of anal incontinence according to age and gender: a systematic review and meta-regression analysis. Int Urogynecol J 2006;17:407-17.

12. Nygaard I, Barber M, Burgio $\mathrm{K}$, et al. Prevalence of symptomatic pelvic floor disorders in US women. JAMA 2008;300:1311-16.

13. Whitehead W, Borrud L, Goode P, et al. Fecal incontinence in US adults: epidemiology and risk factors. Gastroenterology 2009:137:512-17.

14. Pollack J, Nordenstam J, Brismar S, et al. Anal incontinence after vaginal delivery. A five-year prospective cohort study. Obstet Gynecol 2004:104:1397-402.

15. Perry S, Shaw C, McGrother C, et al. Prevalence of faecal incontinence in adults aged 40 years or more living in the community. Gut 2002;50:480-4.

16. Walter $\mathrm{S}$, Hallböök $\mathrm{O}$, Gotthard $\mathrm{R}$, et al. A population-based study on bowel habits in a Swedish community: prevalence of faecal incontinence and constipation. Scand J Gastroenterol 2002;37:911-16.

17. Quander CR, Morris MC, Melson J, et al. Prevalence of and factors associated with fecal incontinence in a large community study of older individuals. Am J Gastroenterol 2005;100:905-9.

18. Melville JL, Fan MY, Newton $\mathrm{K}$, et al. Fecal incontinence in US women: a population-based study. Am J Obstet Gynecol 2005;193:2071-6.

19. Bharucha $A E$, Zinsmeister AR, Schleck $C D$, et al. Bowel disturbances are the most important risk factors for late onset fecal incontinence: a population-based case-control study in women. Gastroenterology 2010;139:1559-66.
20. Botlero R, Bell RJ, Urquhart DM, et al. Prevalence of fecal incontinence and its relationship with urinary incontinence in women living in the community. Menopause 2011;18:685-9.

21. Bols EM, Hendriks EJ, Berghmans BC, et al. A systematic review of etiological factors for postpartum fecal incontinence. Acta Obstet Gynecol Scand 2010;89:302-14.

22. Nichols C, Ramakrishnan V, Gill E, et al. Anal incontinence in women with and those without pelvic floor disorders. Obstet Gynecol 2005;106:1266-71.

23. Ha K, Dancz C, Nelken R, et al. Colorectal and anal symptoms in women with urinary incontinence and pelvic organ prolapse. Int Urogynecol J Pelvic Floor Dysfunct 2010;21:187-91.

24. Bohle B, Belvis $\mathrm{F}$, Vial M, et al. Menopause and obstetric history as risk factors for fecal incontinence in women. Dis Colon Rectum 2011:54:975-81.

25. Slieker-ten Hove MC, Pool-Goudzwaard AL, Eijkemans MJ, et al. The prevalence of pelvic organ prolapse symptoms and signs and their relation with bladder and bowel disorders in a general female population. Int Urogynecol J Pelvic Floor Dysfunct 2009:20:1037-45

26. Gonzalez-Argente FX, Jain A, Nogueras JJ, et al. Prevalence and severity of urinary incontinence and pelvic genital prolapse in females with anal incontinence or rectal prolapse. Dis Colon Rectum 2001:44:920-6.

27. Erekson E, Sung V, Myers D. Effect of body mass index on the risk of anal incontinence and defecatory dysfunction in women. Am J Obstet Gynecol 2008;198:596.e1-4.

28. Burgio K, Richter $\mathrm{H}$, Clements $\mathrm{R}$, et al. Changes in urinary and feca incontinence symptoms with weight loss surgery in morbidly obese women. Obstet Gynecol 2007;110:1034-40.

29. Maleki D, Locke GR 3rd, Camilleri M, et al. Gastrointestinal tract symptoms among persons with diabetes mellitus in the community. Arch Intern Med 2000;160:2808-16.

30. Brittain K, Perry S, Shaw C, et al. Isolated urinary, fecal, and double incontinence: prevalence and degree of soiling in stroke survivors. $J$ Am Geriatr Soc 2006;54:1915-19.

31. Ebbesen MH, Hannestad YS, Midthjell K, et al. Diabetes related risk factors did not explain the increased risk for urinary incontinence among women with diabetes. The Norwegian HUNT/EPINCONT study. BMC Urol 2009;10:11.

32. Chassagne P, Landrin I, Neveu C, et al. Fecal incontinence in the institutionalized elderly: incidence, risk factors, and prognosis. Am $J$ Med 1999;106:185-90.

33. Ryhammer AM, Bek KM, Laurberg S. Multiple vaginal deliveries increase the risk of permanent incontinence of flatus urine in normal premenopausal women. Dis Colon Rectum 1995;38:1206-9.

34. Nelson RL. Epidemiology of fecal incontinence. Gastroenterology 2004:126(1 Suppl 1):S3-7.

35. Richter HE, Burgio KL, Clements $\mathrm{RH}$, et al. Urinary and anal incontinence in morbidly obese women considering weight loss surgery. Obstet Gynecol 2005;106:1272-7. 


\section{Correction}

Rømmen K, Schei B, Rydning A, et al. Prevalence of anal incontinence among Norwegian women: a cross-sectional study. BMJ Open 2012;2:e001257. The segmentation of the fourth author's name in this article was published incorrectly. The correct author name is Sultan AH. We apologise for this error.

BMJ Open 2012;2:e001257corr1. doi:10.1136/bmjopen-2012-001257corr1 